\title{
Trajetórias de Aprendizagem nos Anos Finais do Ensino Fundamental: um relato sobre a adaptação do ensino presencial para o remoto emergencial
}

\author{
Raquel Machado Leite ${ }^{1}$, Alba Valeria Sant Anna ${ }^{1}$, Alex Eder da Rocha Mazzuco ${ }^{1}$, \\ Paula Fogaça Marques Abrahão ${ }^{1}$, Raquel Salcedo Gomes ${ }^{1}$ \\ ${ }^{1}$ Programa de Pós-graduação em Informática na Educação - Universidade Federal do Rio \\ Grande do Sul (UFRGS) - Porto Alegre - RS - Brazil \\ \{tpraquel, alba.portugues, alexmazzuco, paulafogacamarques, raquelsalgo\} \\ egmail.com
}

\begin{abstract}
Faced with the scenario of social distancing caused by the pandemic of COVID-19, there was an urgency in the search for the adaptation of teaching methods mediated by digital technologies. In this sense, this article reports the path taken by a municipal public school, in the final years of elementary school, so that access to basic education could be maintained at that time. The methodology starts from the descriptive principle, narrating the main actions for the development of the work. The results are partial, since the process is taking place, however, we seek to share experiences from this new scenario, fomenting ideas of computational resources and practical pedagogical experiences.
\end{abstract}

Resumo. Diante do cenário de distanciamento social ocasionado pela pandemia da COVID-19, houve urgência na busca pela adaptação de métodos de ensino mediados pelas tecnologias digitais. Nesse sentido, este artigo relata o caminho percorrido por uma escola pública municipal, nos anos finais do ensino fundamental, para que o acesso à educação básica pudesse ser mantido nesse momento. A metodologia parte do princípio descritivo, narrando as principais ações para o desenvolvimento do trabalho. Os resultados são parciais, uma vez que o processo está ocorrendo, entretanto, buscam-se compartilhar as experiências nesse novo cenário, fomentando ideias de recursos computacionais e vivências pedagógicas práticas.

\section{Introdução}

A educação básica regular sempre ocorreu de forma presencial e síncrona, uma vez que se compreende a interação social nesses primeiros anos de educação como fundamental para formação global do indivíduo. Tal entendimento é destacado na redação dos Parâmetros Nacionais de Qualidade para a Educação Infantil: "a interação social tornase o espaço de constituição e desenvolvimento da consciência do ser humano desde que nasce" (BRASIL, 2006a, p. 14). Entretanto, abruptamente, com a presença da COVID19 , as trocas sociais tiveram de ser interrompidas e formas diferenciadas de conduzir o processo de ensino-aprendizagem, respeitando o distanciamento social demandado pela situação de pandemia, precisaram ser estabelecidas. 
Se, em um cenário de normalidade, os recursos computacionais não eram considerados essenciais para a significação da aprendizagem na educação básica, em pouco tempo os aplicativos de comunicação e as redes sociais tornaram-se elementoschave para a continuidade do processo. Desta forma, gestores, coordenadores e professores foram desafiados a buscar soluções para adaptar os saberes curriculares a uma forma palatável e adequada às interfaces de informação e comunicação, fazendo uso das ferramentas digitais em favor da educação, no que tem sido chamado, nesse período, como Ensino Remoto Emergencial (ERE) (HODGES et al., 2020).

A questão decorrente é que, na teoria, os planejamentos dos professores já deveriam contemplar interfaces de comunicação e informação, como suporte ao desenvolvimento do ensino nos componentes curriculares, conforme prescreve a quinta competência da Base Nacional Comum Curricular (BNCC) (BRASIL, 2017), entretanto, o que se observava em muitos espaços era um distanciamento entre o currículo proposto e o currículo vivido. O desenvolvimento de competências, tal como se conceitua na Base, como a capacidade de mobilização para aplicar conhecimentos, habilidades e atitudes a fim de resolver problemas e praticar a tomada de decisão (BRASIL, 2017) aparentava não ter sido uma construção cotidiana no processo de ensino desenvolvido até então. É a partir dessa necessidade curricular que se desenvolve o presente relato, considerando o seguinte questionamento como balizador: como a competência 5, descrita na BNCC, tornou-se essencial para uma adaptação do ensino presencial para o ensino remoto emergencial, no período de pandemia?

Buscando desenvolver essa reflexão, o texto assume a seguinte estrutura: inicialmente, há uma apresentação das competências gerais da BNCC, considerando a perspectiva das Tecnologias da Informação e Comunicação (TICs) na educação. Em sequência, descreve-se o cenário empírico da pesquisa, bem como os recursos, métodos e trajetórias de aprendizagem construídas para desenvolver o processo de ensinoaprendizagem remoto e, por último, apresenta-se uma análise parcial do que se tem até o momento.

\section{A BNCC e as TICs na Educação}

O desenvolvimento das TICs tem modificado os modos de vida humanos em diferentes âmbitos, dentre eles, os processos de aprendizagem, que assumem características colaborativas e coletivas. Lemos e Lévy (2010, p. 45) descrevem que a "aprendizagem coletiva se dá pelo princípio da colaboração em rede", destacando o papel dos softwares e das mídias para favorecer a disseminação do conhecimento e o compartilhamento de informações, mas ressaltam a dificuldade da democratização do acesso ao desenvolvimento tecnológico e a toda essa informação disponibilizada em rede.

A escola emerge como responsável por cumprir o desafio de promover uma "inclusão digital" e desenvolver saberes científicos e tecnológicos ao longo da educação básica, sendo a BNCC o documento normatizador para a construção das trajetórias de aprendizagem dos estudantes. Trajetórias, essas, compreendidas como percursos de aprendizagem conceitual, desenvolvidas de forma imbricada (CANTO, et al. 2016), a serem construídas em cada componente curricular, visando ao desenvolvimento das competências gerais do aluno, a fim de que tais conhecimentos possam inseri-lo em um contexto de desenvolvimento pessoal adequado às demandas da vida, do mercado de 
trabalho e de uma perspectiva cidadã, compreendidos como desafio de nossa sociedade (BRASIL, 2017). O desenho metodológico da BNCC favorece que cada componente curricular promova, de forma interdisciplinar, o uso de tecnologias no processo de ensino-aprendizagem, reforçando o papel da escola em "selecionar, produzir, aplicar e avaliar recursos didáticos e tecnológicos para apoiar o processo de ensinar e aprender" (BRASIL, 2017, p. 17). A partir desses objetivos, lê-se como competência geral a ser desenvolvida no item 5 da Base:

\begin{abstract}
Compreender, utilizar e criar tecnologias digitais de informação e comunicação de forma crítica, significativa, reflexiva e ética nas diversas práticas sociais (incluindo as escolares) para se comunicar, acessar e disseminar informações, produzir conhecimentos, resolver problemas e exercer protagonismo e autoria na vida pessoal e coletiva. (BRASIL, 2017, p. 9)
\end{abstract}

Essa competência torna o uso de TICs na educação básica não mais uma escolha, mas uma necessidade curricular. Ocorre que nem sempre os professores estão familiarizados com as TICs. Muitas vezes, a própria escola proíbe o uso de celulares, vídeos e computadores, o que se caracteriza como incoerência, uma vez que:

[...] hoje a mobilidade da comunicação é algo presente no cotidiano das pessoas. Dentre as tecnologias móveis o celular é o mais difundido, modificando a relação homem-máquina de tal forma, em que ocorrem entrelaçamentos até o ponto onde possa não existir uma separação clara. (CORRÊA et al., 2019, p. 732)

Quanto ao cenário empírico deste relato, as interfaces de comunicação não se configuravam como recursos utilizados no processo de ensino cotidiano da escola, o que tornou a adaptação de uma modalidade totalmente presencial, para um modelo remoto, um desafio. Hodges et al. (2020) afirmam que mover a educação presencial para online pode permitir a flexibilidade de ensinar e aprender em qualquer lugar, a qualquer hora, mas a velocidade com que essa mudança para a educação online deve ocorrer é sem precedentes.

\title{
3. Métodos
}

A pesquisa caracteriza-se como estudo descritivo, um relato de experiência em relação aos aspectos pedagógicos e tecnológicos envolvidos no processo de adaptação entre o ensino presencial e o remoto emergencial durante a pandemia. A narrativa dessa adaptação deu-se por meio de um recorte temporal, contemplando o período de 17/02/2020 a 25/06/2020, ocorrido em uma escola pública municipal do interior do Rio Grande do Sul (RS). ${ }^{1}$

Para sistematizar a metodologia de adaptação, foi elaborado um fluxograma (Figura 1), compreendendo as principais etapas desenvolvidas, segmentadas em três fases. A Fase 1 inicia com a etapa de diagnóstico do momento, na tentativa de buscar uma melhor compreensão dos principais acontecimentos relacionados tanto ao cenário pedagógico quanto ao tecnológico. Para isso, foram realizadas pesquisas bibliográficas, reuniões com integrantes da equipe diretiva e pedagógica da escola, bem como com os responsáveis pelo apoio tecnológico.

\footnotetext{
${ }^{1}$ Escola Municipal de Ensino Fundamental Professor Arno Nienow, localizada na cidade de Dois Irmãos/RS.
} 


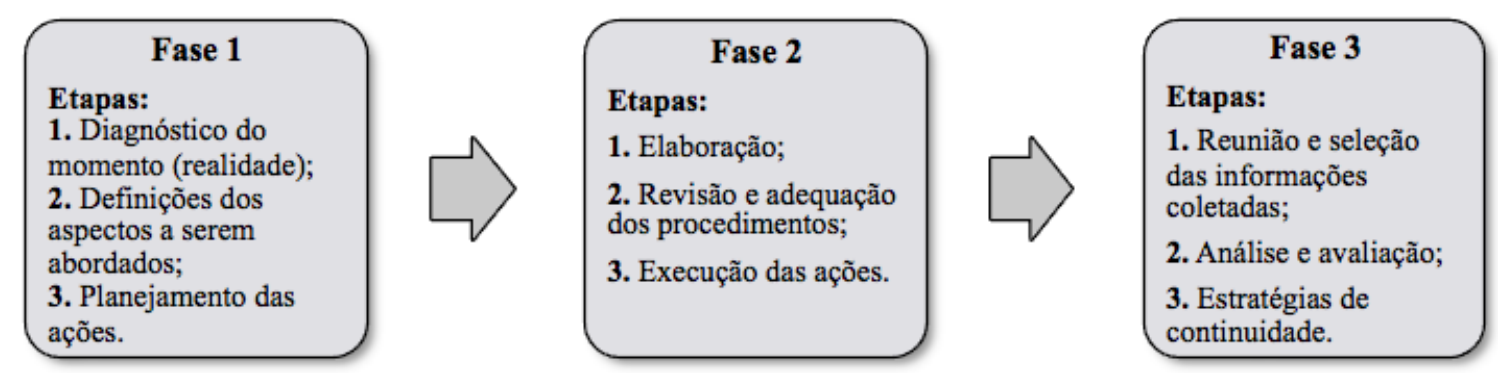

Figura 1. Sistematização da metodologia.

Com as informações da primeira etapa, foi possível definir os principais aspectos a serem abordados no trabalho (segunda etapa). Foram contemplados, dessa forma, os aspectos pedagógicos e tecnológicos essenciais, presentes no período de adaptação para as atividades remotas. Entre eles, por exemplo, estão os métodos de preparação do material de ensino e sua postagem em um ambiente virtual, as técnicas adequadas de configuração desse ambiente e a análise dos recursos tecnológicos de cada usuário, incluindo alunos, professores e equipe pedagógica.

$\mathrm{Na}$ sequência, ocorreu a execução da terceira etapa, em que foram planejadas as ações considerando os elementos relacionados a cada aspecto. Foi definido que, ao menos, deveriam intercorrer duas reuniões (uma direcionada a cada aspecto); a essencialidade do adequado acompanhamento do trabalho do maior número possível de professores; a necessidade da elaboração de um roteiro, com o objetivo de conduzir cada reunião; a indispensabilidade de um ou mais instrumentos de captação de informações pedagógicas e tecnológicas e; por fim, a decisão de encontros semanais entre os pesquisadores, visando a discussão das informações disponíveis até o momento e (re)planejamento de novas ações.

Ao iniciar a Fase 2, na primeira etapa, Elaboração, foram definidas e agendadas duas novas reuniões com duas representantes da direção e com uma coordenadora pedagógica da escola, fazendo uso de um roteiro, norteando as discussões acerca dos aspectos pedagógicos e tecnológicos. Do mesmo modo, em relação a estes, foram estabelecidas reuniões específicas com especialistas responsáveis pelo apoio tecnológico escolar. Foi determinado que o acompanhamento do trabalho docente seria realizado abrangendo um grupo de 12 professores, que atendem 103 alunos, distribuídos nos anos finais do ensino fundamental. Como instrumentos de captação informacional, foram estipulados o uso de e-mail (com compartilhamento no drive) e redes sociais. $\mathrm{Na}$ segunda etapa, todos os procedimentos foram revisados e, quando necessário, readequados. Na terceira etapa, todas as ações previstas foram executadas.

$\mathrm{Na}$ primeira etapa da Fase 3, foram reunidas todas as informações coletadas, independentemente de sua relevância. Consideraram-se documentos como diários, relatórios, explanações de servidores da escola, etc. Na sequência, na segunda etapa, foi realizada a análise e a avaliação das informações, em que critérios de exclusão foram adotados, como documentos repetidos, informações não condizentes com os aspectos abordados, dados não passíveis de comprovação, etc. Como última etapa, foram estipuladas estratégias de continuidade, com o intuito de, ao término desse trabalho, dar-se prosseguimento a novas pesquisas. Nas próximas seções, juntamente com o relato, é exposto o resultado parcial do processo metodológico. 


\section{O Cenário Empírico}

\subsection{Caracterização da Escola e das Turmas}

A Escola Municipal de Ensino Fundamental está localizada no interior do RS, atendendo em sua maioria filhos de trabalhadores do setor calçadista, base da economia local. Atualmente, conta com 430 alunos, matriculados desde a Educação Infantil aos Anos Finais do Ensino Fundamental. Atuam na instituição 56 servidores. Esse relato compreende um recorte de 103 alunos, distribuídos em 07 turmas dos Anos Finais.

\subsection{Implementação do Ensino Remoto Emergencial: Principais Datas e Acontecimentos}

O ano letivo da rede municipal iniciou-se no dia 17/02/2020. Os trabalhos ocorreram normalmente até 20/03/2020, quando a Prefeitura decretou estado de calamidade pública em função do primeiro caso de COVID-19 registrado na cidade. As aulas foram suspensas a partir do dia 23/03/2020. Em 13/04, foi divulgada a Comissão de Discussão do Calendário Escolar com representantes de todos os segmentos das unidades educativas. Em 23/04, foi divulgado o resumo da primeira reunião da Comissão de Discussão do Calendário Escolar, contando com várias questões que traziam à luz incertezas do momento vivido, pois nessa data ainda não havia legislação específica para o retorno das atividades não presenciais.

O Conselho Nacional de Educação (CNE) autorizou a reorganização do calendário escolar e a possibilidade de cômputo de atividades não presenciais no dia 28/04/2020, com a emissão do Parecer CNE-CP n ${ }^{\circ} 5$, que estabelecia o cumprimento da carga horária mínima anual. Em 04/05/2020, o Diário Oficial da União publicou a aprovação do referido parecer, auferindo amparo legal para o novo modelo de ensino, desobrigando o cumprimento dos 200 dias letivos no ensino fundamental, mas requerendo o cumprimento da carga horária mínima anual de 800 horas. A partir dessa homologação, gestores e profissionais da educação passaram a traçar estratégias de caráter emergencial. No dia 29/04, a Secretaria de Educação emitiu comunicado à comunidade em geral, informando que seria aplicada uma pesquisa via Facebook para verificar o contexto tecnológico das famílias. Para tanto, todas as escolas municipais foram orientadas a criar uma página na referida rede social. A partir desse momento foi iniciada a adaptação para utilização das tecnologias no contexto escolar. Como resultado da pesquisa de levantamento na Escola Arno Nienow, junto aos alunos dos Anos Finais do Fundamental, foram obtidos 91 retornos, demonstrados na Tabela 1:

Tabela 1. Contexto tecnológico das famílias

\begin{tabular}{|l|c|c|c|c|c|}
\hline Turmas & $\begin{array}{c}\mathrm{N}^{\mathrm{o}} \text { de } \\
\text { Alunos }\end{array}$ & $\begin{array}{c}\mathrm{N}^{\mathrm{o}} \text { de alunos com } \\
\text { acesso ao celular e } \\
\text { WhatsApp }\end{array}$ & $\begin{array}{c}\mathrm{N}^{\mathrm{o}} \text { de alunos com } \\
\text { computadores } \\
\text { em casa }\end{array}$ & $\begin{array}{c}\mathrm{N}^{\mathrm{o}} \text { de alunos } \\
\text { com acesso à } \\
\text { Internet na } \\
\text { residência }\end{array}$ & $\begin{array}{c}\mathrm{N}^{\mathrm{o}} \text { de alunos } \\
\text { sem acesso à } \\
\text { Internet na } \\
\text { residência }\end{array}$ \\
\hline $6^{\circ}$ Ano & 26 & 22 & 17 & 22 & 1 \\
\hline $7^{\circ}$ Ano & 26 & 23 & 13 & 23 & 0 \\
\hline $8^{\circ}$ Ano & 21 & 19 & 16 & 19 & 0 \\
\hline
\end{tabular}




\begin{tabular}{|l|c|c|c|c|c|}
$9^{\circ}$ Ano & 20 & 18 & 8 & 18 & 0 \\
\hline Progressão & 10 & 8 & 4 & 8 & 0 \\
\hline Total & $\mathbf{1 0 3}$ & 90 & 58 & 90 & 1 \\
\hline \multicolumn{2}{l}{ Total de Retornos } \\
\hline
\end{tabular}

Como é possível observar, na Tabela 1, dos 103 alunos, 91 responderam à pesquisa, sendo que 90 disseram ter acesso à Internet em sua residência, bem como, utilizam celular e WhatsApp, 58 também possuem computador, enquanto 01 informou não possuir acesso à Internet. A partir desse contexto, iniciaram-se debates e delineamentos de estratégias para o reinício dos trabalhos no método de educação remota emergencial. Em 30/04, foi expedido novo comunicado da prefeitura, esclarecendo a impossibilidade do retorno às aulas presenciais no dia $05 / 05$, foi também divulgada a proposta de calendário escolar com retorno a partir de 01/06. Também, em 30/04, por meio do Programa A União Faz a Vida, iniciou-se a primeira formação online para os professores da escola, com duração até 28/05 sobre a plataforma Google Classroom, a ser utilizada como ambiente virtual de aprendizagem durante a pandemia. A principal intenção da formação foi familiarizar os professores à utilização do ambiente para o posterior trabalho com aulas remotas.

Em 11/05, iniciou-se a segunda formação pedagógica online, sob responsabilidade do Instituto Ivoti, com palestras sobre a ressignificação do processo de ensino-aprendizagem e a apresentação de ferramentas tecnológicas práticas para utilização no contexto educativo. Em 18/05 foi o marco inicial do retorno às atividades remotas com os alunos. Primeiramente, foi realizado chamamento à comunidade escolar via Facebook, orientando o acesso às atividades para retomada de vínculo, através de vídeos gravados pelos professores. As tarefas foram organizadas em roteiro. A cada semana, novas atividades são disponibilizadas e os alunos possuem 07 dias para estudar e entregar. Nessa data ainda não havia sido realizada a migração para a plataforma educacional, então, os materiais foram disponibilizados via blog oficial da escola e por aplicativo de mensagens WhatsApp Business, cadastrado com o telefone convencional da Instituição. Os alunos sem acesso às tecnologias possuem a opção de retirar os mesmos materiais, presencialmente, na escola. A primeira formação técnica do Google for Education, voltada aos professores de informática educativa, ocorreu em $19 / 05$.

A primeira live de apresentação da plataforma, direcionada a todos os professores, realizou-se em 21/05. Como escola pioneira da rede municipal de ensino, iniciou os testes de postagem de conteúdos no Google Classroom no dia 22/05. Inicialmente, houve interação com a classe do $9^{\circ}$ ano, gradualmente alcançando outras turmas nos dias posteriores. A partir de 22/05, a formação foi direcionada a dois profissionais de cada escola, sendo um deles a técnica de apoio pedagógico e o outro um professor de informática educativa. A empresa GetEdu, parceira oficial do Google Education no Brasil, foi a encarregada de ministrar o curso. Os dois profissionais escolhidos de cada escola são responsáveis pela multiplicação do conhecimento aos colegas. Em 26/05, foi realizada a primeira replicação do Google Classroom, via 
Google Meet, aos professores do $6^{\circ}$ ao $9^{\circ}$ ano. Após, semanalmente, são realizadas webconferências com professores e/ou alunos, dentro das necessidades apresentadas.

Um novo calendário escolar foi publicado em 01/06, contabilizando as horas presenciais já aplicadas nos meses de fevereiro e março, horas não presenciais dos meses de maio, junho e julho e considerando um possível retorno presencial em agosto. Nessa mesma data foi emitido comunicado da Federação das Associações de Municípios do Rio Grande do Sul (FAMURS), ressaltando que o retorno às atividades presenciais escolares dependem dos cenários apresentados, de acordo com a evolução da pandemia, sendo antecipadas ou adiadas, conforme o resultado de pesquisa encomendada pelo governo do estado à Universidade Federal de Pelotas. Em 25/06, o governador do estado do RS emitiu comunicado informando abertura de consulta pública com entidades ligadas à educação para decisão conjunta sobre um possível retorno às aulas no mês de agosto, o que definirá o futuro das escolas públicas e privadas no estado.

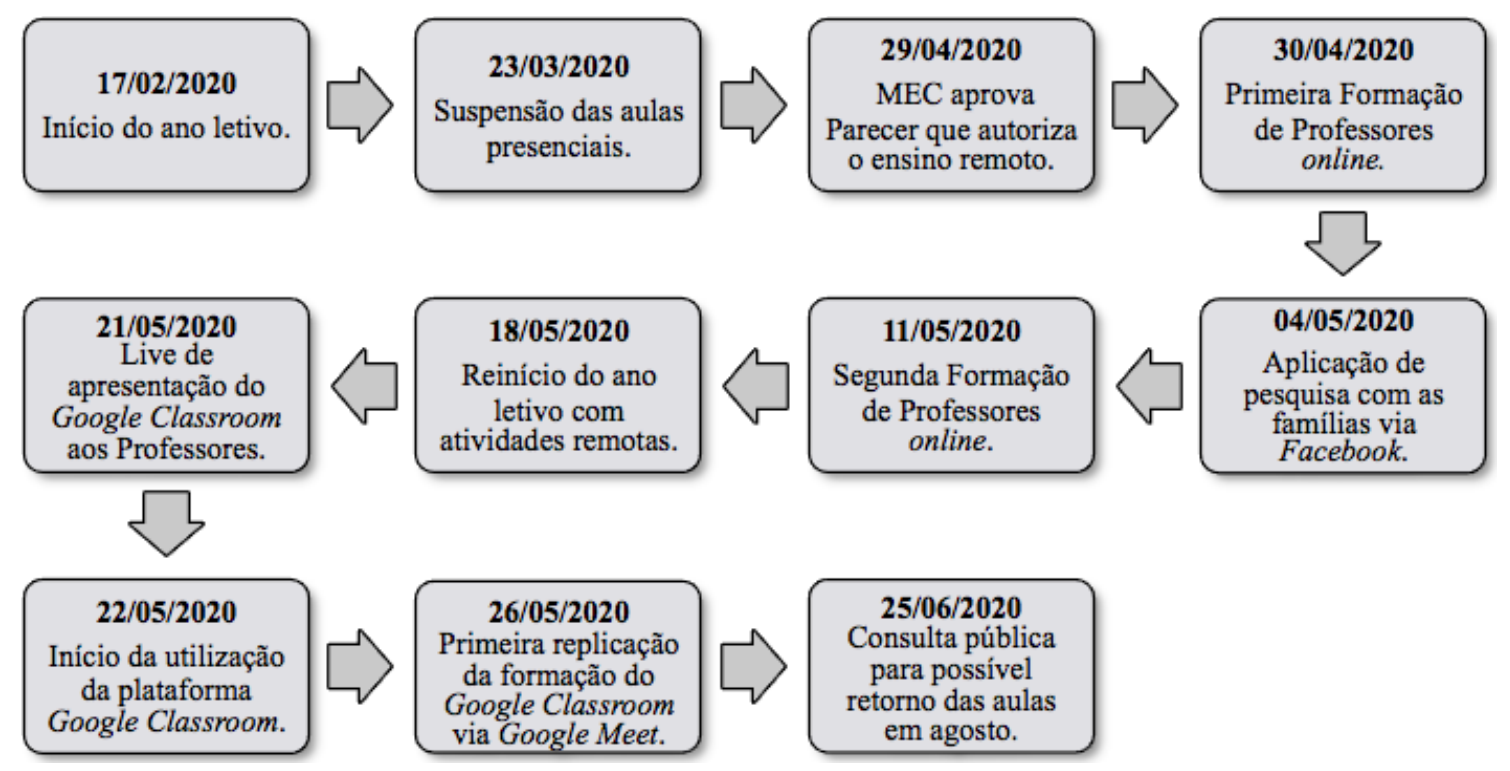

Figura 2. Linha do Tempo.

\subsection{Ferramentas Utilizadas}

Inicialmente, como consta no relato e na linha do tempo, a primeira ferramenta utilizada foi a rede social Facebook, na qual gestão, coordenação pedagógica e professores retomaram o vínculo com a comunidade escolar com mensagens em vídeo. O blog oficial da escola e o WhatsApp Business foram as duas outras ferramentas aplicadas para a reconstrução dos laços. No app de troca de mensagens, os alunos foram divididos em suas respectivas turmas, recebendo materiais e orientações específicas para cada classe. Os retornos de mensagens à escola pelo aplicativo são recebidos com o nome e turma de cada aluno, o que facilita a identificação do remetente. Após as formações de professores, foi disponibilizado no site da Prefeitura um tutorial para que alunos e professores criassem seu e-mail institucional, viabilizado pelo Gmail, para que pudessem acessar a plataforma Google Classroom, a quarta ferramenta e o principal ambiente de aprendizagem utilizado nesse transcurso. 
Os conteúdos e atividades são postados semanalmente no ambiente Google Classroom, no blog oficial da escola, no qual cada turma possui sua respectiva página. São também enviados pelo WhatsApp e entregues presencialmente na escola àqueles educandos que não possuem acesso às tecnologias. As postagens na página do Facebook ficam sob responsabilidade da gestão escolar e da professora de informática educativa, a entrega de materiais de forma presencial é realizada pela gestão e equipe pedagógica, que continuaram trabalhando e cumprindo carga horária normal, fisicamente na escola. As publicações no blog estão a cargo da professora de informática e, na sala de aula virtual do Google, são realizadas pelos professores, cada um em sua respectiva disciplina.

O uso da plataforma educacional encorajou alguns professores a desenvolverem métodos de ensino diferentes do que estavam acostumados no início do ano letivo. A professora de Ciências criou um canal no YouTube e, utilizando o aplicativo Inshot para edição de vídeos no celular. Passou a publicar seus experimentos de forma dinâmica e na linguagem que os estudantes vivenciam diariamente nas redes, alcançando mais de 290 visualizações em algumas produções. Sua disciplina se tornou a que mais recebe retorno de atividades. Alguns colegas perceberam e, aos poucos, também estão se aventurando, criando seus canais e publicando materiais em vídeo. A professora de língua alemã utiliza podcasts no idioma para que seus alunos possam treinar a pronúncia correta das palavras, com os áudios ficando armazenados na plataforma online Soundcloud, disponibilizados por meio de links.

O Drive, serviço de armazenamento e sincronização de arquivos em nuvem do Google, e seus aplicativos são muito utilizados por professores e alunos para a construção de documentos de textos e apresentações colaborativas. Os textos construídos pelos professores, em sua maioria, são feitos utilizando o recurso de digitação por voz do Documentos Google. A funcionalidade é popular entre os docentes, pois reduz consideravelmente o tempo gasto em digitação e a fadiga ocular provocada pela luz dos equipamentos. A utilidade do Drive também se dá no compartilhamento das aulas semanais pelos professores com a coordenação pedagógica.

Aulas de apoio técnico aos alunos via Google Classroom são realizadas no Meet, serviço de comunicação por vídeo do Google. São agendadas para cada turma semanalmente, programadas no Google Agenda. Os participantes recebem e-mails com convites e são notificados antes do início. As responsáveis pelos contatos são a professora de informática educativa e a técnica de apoio pedagógico, que também convidam os professores das disciplinas para que se façam presentes nesses momentos. A intenção é que os estudantes tragam suas dúvidas quanto à utilização da plataforma e postagens de materiais e, assim, mantenham o vínculo durante o distanciamento imposto.

\subsection{Problemas Diagnosticados}

As demissões no setor calçadista geraram um problema: falta de recursos financeiros nas famílias dos alunos, o que obrigou a exclusão do acesso à Internet, pois não é um item de primeira necessidade. Anteriormente à pandemia, a prefeitura disponibilizava acesso gratuito à Internet em locais públicos como praças e parques, entretanto, para evitar aglomerações, esse serviço também foi suspenso. Tudo isso gera um problema de 
retorno. Em determinadas turmas, um número considerável de alunos não devolve as atividades. Ainda não se tem o percentual exato das devolutivas, devido às tarefas em atraso. Além da falta de acesso, muitas famílias estão indo embora da cidade e não se sabe exatamente quantos alunos matriculados irão de fato continuar. Pais dirigiram-se à escola, emocionalmente abalados, para comunicar mudança de cidade, todavia, não é possível definir precisamente quantos não comunicaram suas partidas.

Outro item relevante a ser considerado são os equipamentos tecnológicos utilizados pelas famílias. Muitas vezes, o celular ou computador não possui softwares compatíveis ou memória suficiente para decodificar e/ou armazenar os arquivos enviados pelos professores. Para facilitar o retorno, os docentes permitem que os alunos façam as tarefas no caderno e, após, enviem fotos das mesmas, entretanto, nem todos possuem câmeras digitais. Os prazos para realização das atividades são de uma semana, porém, devido ao elevado número de percalços, poucas são enviadas dentro do prazo.

\title{
4.5 Avaliação da Aprendizagem
}

Os fatores elencados previamente tornam a avaliação um fator em aberto. Diante da realidade que se apresenta, ainda não se chegou a um consenso e o principal questionamento relaciona-se à forma mais adequada de avaliar a aprendizagem sem que nenhum aluno seja excluído do processo. "Brasil (2020a, p. 20) e Brasil (2020b, p. 18), sugerem que:

\begin{abstract}
É importante garantir uma avaliação equilibrada dos estudantes em função das diferentes situações que serão enfrentadas em cada sistema de ensino, assegurando as mesmas oportunidades a todos que participam das avaliações em âmbitos municipal, estadual e nacional. Neste sentido, as avaliações e exames de conclusão do ano letivo de 2020 das escolas deverão levar em conta os conteúdos curriculares efetivamente oferecidos aos estudantes, considerando o contexto excepcional da pandemia, com o objetivo de evitar o aumento da reprovação e do abandono no ensino fundamental e médio.
\end{abstract}

Sob essa perspectiva, o Conselho Municipal de Educação busca encontrar uma solução garantindo o equilíbrio no processo avaliativo, observando o contexto atípico e preservando os objetivos de aprendizagem, as habilidades e as competências.

\section{Conclusões Parciais}

A adaptação da educação presencial para o ensino remoto, com as tecnologias digitais, quebrou paradigmas e se tornou um marco na vida da escola. $O$ ensino remoto emergencial provocou um processo de aprendizagem coletivo, rápido, compartilhado, mútuo, capaz de tornar gestores e professores antes resistentes, incentivadores do uso de tecnologias digitais em favor da educação. Se antes tecnologias eram inseridas pontualmente, nesse momento de transposição de modalidade o professor percebe-se forçado a conduzir o aluno em trajetórias mediadas por interfaces de comunicação. As trajetórias de aprendizagens dos docentes evidenciam-se no relato apresentado devido ao processo de adaptação metodológica proveniente do ERE. Não sendo compreendido como um movimento natural de adequação ao currículo prescrito, por meio de debates e trocas reflexivas de amplo planejamento, mas como uma imposição vertical devido ao contexto de pandemia e a necessidades técnicas. 
Em alguma medida, percebe-se que, devido a essa contingência, a competência descrita no item 5 da BNCC passou a ser incorporada ao cotidiano de professores e alunos. A ressignificação das TICs pode ser percebida quando o blog passa, nesse contexto, a ser um espaço de autoria dos professores, por exemplo. De acordo com as estatísticas de tráfego do Google Analytics, anteriormente às postagens dos materiais, o recurso recebia menos de 50 visualizações mensais. Nos meses de aplicação do ERE, recebe aproximadamente 500 visitas, atingindo, em sua maioria, consumidores de conteúdo oriundos do Brasil, e o que surpreende, também de outros países, como República Tcheca, Estados Unidos, Romênia, Reino Unido e Rússia, o que pode demonstrar que os assuntos publicados podem ser de interesse não somente dos alunos.

Tendo em vista os objetivos iniciais propostos para esse trabalho, pode-se compreender que a trajetória de aprendizagem precisou ser reinventada. Entende-se que a relação entre tecnologias digitais e educação poderá não ser mais a mesma, entretanto, o momento é de ações colaborativas e integradas, pois mesmo que o distanciamento cause a sensação de solidão, a travessia por esse momento acontece em conjunto, em uma tentativa de reagregar a escola pela via da educação online.

\section{Referências}

Brasil, BNCC. Base Nacional Curricular Comum (proposta). Brasília, DF: MEC, 2017.

Brasil. Conselho Nacional de Educação. Parecer CNE/CP N $N^{0}$ 5/2020. Brasília, DF: MEC, 2020a. Disponível em: http://portal.mec.gov.br/index.php?option=com_docm an\&view=download\&alias=145011-pcp005-20\&category_slug=marco-2020-pdf\&Ite mid=30192. Acesso em: 28 abr. 2020.

Brasil. Ministério de Educação e do Desporto. Secretaria de Educação Básica. Parâmetros Nacionais de Qualidade para a Educação Infantil. Brasília, DF: MEC, 2006a. 2.v.

Brasil. Ministério da Educação. Nota Técnica n³2. Brasília, DF: MEC, 2020b. Disponível em: http://www.abrafi.org.br/js/ckeditor/foto_internas/NotaTecnica32ME C.pdf.pdf. Acesso em: 30 jun. 2020.

Canto, A. et al. Trajetórias de Aprendizagem. José Valdeni de Lima \& Colaboradores. Trajetórias de Aprendizagem: Teoria e Prática. 2016.

Corrêa, A. et al. O uso de Mobile Learning e Metodologias Ativas no contexto educacional. In: Anais dos Workshops do Congresso Brasileiro de Informática na Educação. 2019. p. 730.

Hodges, C. et al. A diferença entre ensino remoto de emergência e aprendizado on-line. 2020. Disponível em: https:/er.educause.edu/articles/2020/3/the-difference-bet ween-emerg ency-remote-teaching-and-online-learning. Acesso em: 27 mar. 2020.

Lemos, A.; Lévy, P. O futuro da internet: em direção a uma ciberdemocracia planetária. São Paulo: Paulus, v. 13, 2010. 